great effort is being made to improve matters. The teachers' training centres must be small by British standards, but at present some of them produce less than a dozen teachers annually and lose in both efficiency and economy for that reason. The curriculum followed in the schools has the aim of enabling the Africans to lead the fullest possible life in their own environment, and to improve that environment as quickly as possible; but some Africans would like to copy too closely the aims and methods of European education which are, of course, related to entirely different environment, culture and traditions. Some Africans are also prone to mistake the means for the end and to regard education as designed to enable them to pass examinations rather than to lead a good life. Many people in Great Britain fall into the same error, but it is natural that a people who are emerging from a primitive way of life should be especially open to the temptations of an education academic and examination-ridden. Language is a real difficulty in most of the schools of these territories, for the tribal vernaculars are very numerous, they arise from a number of language roots, and they are often limited to such a small number of users that these languages have little literature and sometimes even no school text-books, simply because the market is too small to make printing economically possible. A lingua franca to be used in addition to the tribal vernaculars is essential to progress, and it must be a lingua franca current over a wide area, with a rich literature and fully equipped for use in technical education and in commerce. Swahili, which has been used to some extent as a lingua franca, fails in some of these respects but has stood in the way of a better common language.

The population of many of these territories is increasing very fast, and increased productivity is essential. There is here a vicious circle, for increased productivity is a condition of the spread of education for financial reasons, while productivity cannot expand rapidly until we have an educated population. So many other things depend on the advance of education in East and Central Africa that the vicious circle thus described must be broken into to raise the moral stature as well as the material resources of these countries, and to enable their inhabitants to lead a fuller life.

\section{BRITAIN'S FOOD SUPPLIES}

$\mathrm{N}$ his presidential address to Section M (Agriculture) Dr. N. C. Wright opens with a reference to the leading part which the British Association has always taken in relating nutritional needs to national life, notably by the pioneer survey of food consumption and expenditure made by a special Committee of the Association in 1880. This survey had already shown the increasing dependence on overseas food supplies which accompanied Britain's rapid industrial development in the nineteenth century. During the fifty years between 1880 and the 1930's this trend was continued, until in the immediate pre-war years Britain relied on imports to the extent of some 70 per cent of the total calorie value of the food supplies. This excessive dependence on overseas supplies was inevitably accompanied by the neglect of the foodproducing potentialities of British agriculture.

With the outbreak of war in 1939 the country had to face drastically reduced overseas food shipments, which by 1942 had fallen to only half the pre-war figure. To meet this serious menace to the food supply it was necessary not only to re-plan the import programme but also to re-develop British agricultural production. From the nutritional aspect there were three main objectives in planning this re-orientation of the country's food supplies: first, to ensure an adequate calorie-level in the national diet; second, to furnish sufficient supplies of 'protective' foods, particularly for the vulnerable groups of the population ; and third, so far as possible to provide a diet which was reasonably varied and palatable. The first objective was achieved by expanding substantially the home production of crops which furnished maximum calories for direct human consumption, for example, wheat, potatoes and sugarbeet. This inevitably involved substantial reductions in the livestock population, notably in the numbers of pigs and poultry - though such reductions were partially offset by large increases in the home output of coarse grains. The second objective was achieved partly by increasing the supplies of liquid milk and subsidizing its consumption, partly by expanding the acreages under vitamin-rich vegetables, and partly by adopting processing techniques designed to increase the 'protective' value of certain staple foods such as bread and margarine. The third objective was achieved by changing the pattern of imports to include a higher proportion of the more palatable and concentrated foods, and by increasing the home production of certain highly flavoured crops. As a result of these combined measures the nutritional value of the diet was actually improved during the War.

The immediate effect of the cessation of war was to create greatly increased demands on the world's available food supplies. Simultaneously Britain had to face the loss of Lend-Lease aid. Since animal products represented the most expensive drain on the country's currency, the main objective of the 1947 agricultural expansion programme was to re-expand the livestock population; but to do so not only on the basis of substantially increased dependence on home-produced animal feeds but also without any appreciable reduction in the home contribution to the total calories of the national diet. The extent to which this was achieved is shown by the figures for home production in 1950 .

Although both the war and post-war increases in home food production were associated with marked changes in the pattern of land usage, they were also largely due to technical improvements designed to increase both yield and productive efficiency. 'These improvements included very substantial increases in fertilizer usage, in farm mechanization, in crop protection methods, and in the productivity of crops and stock, as well as of grassland.

An examination of the country's future food requirements indicates that largely owing to the gradual equalization of demand between different income groups these are likely to increase. At the same time, both the availability of world supplies and Britain's balance of payments problem are likely to limit the country's ability to purchase food from overseas. The need for a further expansion in home production is therefore assured. Whether such expansion will involve a further marked re-orientation in the pattern of land usage cannot be forecast, but there is no doubt that even within the present pattern there is still ample scope for improvement by the wider application of science to farming practice. 